\title{
"Impressive Scenery of Shanxi" galas held in Shanxi to promote tourism development
}

Shanxi Province in North China is rich in tourism resources, with a variety of historical, natural, and city sites throughout the province, including the Great Wall, canyons border road, forests, alpine meadows, caves, lakes, waterfalls, hot springs, grottoes, ancient tombs, an ancient city, cultural relics, museums, and major modern construction landscape achievements. Shanxi has a 3000-year written history and is renowned for hosting a museum dedicated to ancient Chinese culture. More than 18000 existing ancient buildings constructed before the Song Dynasty have been found, accounting for $70 \%$ of the pre-Song Dynasty buildings in China.

Developing tourism resources is an important policy focus in the economic growth of the province. To promote tourism development, the second season of "Impressive Scenery of Shanxi" galas were broadcast on television from April to June 2017. These galas were organized by the Shanxi Tourism Development Committee and Shanxi Radio and Television.

The tourism-themed "Impressive Scenery of Shanxi" galas were filmed at ten famous scenic locations, which are described as follows. (1) Pingyao Ancient City, a world heritage site. As an ancient cultural city with more than 2700 years of human history, Pingyao is a large architectural complex that is a good example of an ancient building system in China. (2) Niangziguan Pass of the Great Wall is a world heritage site, one of China's major passes, and Shanxi's eastern gate. (3) Yanmenguan Pass of the Great Wall, a world heritage site. The pass controls the path from the agricultural to animal husbandry regions in Shanxi. (4) Wooden Tower of Yingxian County, the highest and oldest wooden tower building in China. It is the conservation host for rare historic relics from the Liao Dynasty. (5) Grand Canyon of the Huguan Taihang Mountains. The canyon, which stretches more than $40 \mathrm{~km}$, has a relative altitude difference of $200 \mathrm{~m}$ to $800 \mathrm{~m}$, with vertical cliffs and horizontal canyons. (6) The Royal Prime Minister's Palace, which was the mansion of Chen Tingjing, a famous prime minister of the Qing Dynasty. It covers a sightseeing area of more than 36 square kilometers. (7) Guanque Tower, a famous scenic spot for climbing. Many ancient poets climbed the tower for an infinite view and left a wealth of poetry to later generations. The "Ascending Guanque Tower", penned by Wang Zhihuan during the Tang Dynasty, survived for thousands of years and is enjoyed by thousands of households today. (8) The Yunqiu Mountain Scenic Spot was filmed for its breathtaking sightseeing. A great number of people visit the Yunqiu Mountain every year for the Zhonghe Festival. (9) Jiajiazhuang Village is a famous cultural and ecological tourism scenic town and agricultural sightseeing area in Shanxi. (10) Shanxi Grand Theater, Taiyuan. Situated in the new district of Changfeng, Taiyuan, it is an element of social and urban identity and iconic building for the city of Taiyuan.

A delegation composed of interested media and tourism experts inspected tourism development in the ten cities of Shanxi in 2017 to evaluate potential scenic locations. Eight evaluation points were examined, including tourism transportation, travel accommodation, tourism environment, tourism products, public services, knowledge tourism, market order, and publicity marketing. The delegation received reports describing the tourism status from each municipal tourism development committee in the ten cities and proposed corresponding suggestions for improving tourism management in this province. 